\title{
Nanostructured Metal Oxides for High-Temperature Gas Sensing: Structural Stabilization in Porous Metal Oxides
}

\author{
Dominik Klaus, Michael Tiemann, Thorsten Wagner \\ Universität Paderborn, Naturwissenschaftliche Fakultät, Department Chemie \\ Warburger Straße 100, D-33098 Paderborn, Germany \\ dominik.klaus@uni-paderborn.de
}

\begin{abstract}
As recently shown, nanostructured $\mathrm{SnO} 2$ and In2O3 prepared by nanocasting exhibit higher thermal structural stability than their non-ordered counterparts [1,2].In the presented work we will show a correlation of the thermal stability with the crystallite size of the nanostructure. In2O3is utilized as model material since preparation of nanocast phases with variable crystallite sizes is possible [3]and it is a qualified sensing material [4]. Two samples with different crystallite sizes but otherwise comparable structural features are thermally treated stepwise in a temperature range between $250^{\circ} \mathrm{C}$ and $700^{\circ} \mathrm{C}$. The specific surface area (BET) is observed as a probe for the structural integrity of the material. Results show a shift of the mesostructure breakdown (steep decrease in BET surface area) to higher treatment temperatures for the sample with the larger lateral crystallite size. This breakdown is attributed to a coalescence-based growth mechanism. A linear decrease in surface area observed for both samples is assigned to Ostwald ripening which leads to a smoothing of the inner surfaces and a sealing of the micropores in the walls of the nanocast material.
\end{abstract}

Key words: metal oxide, nanocasting, mesoporous, thermal stability, Indium Oxide, high temperature

\section{Introduction}

Signal stability of semiconducting gas sensors depends strongly on the structural parameters of the sensing layer [5]. Most nanostructures are not applicable as high-temperature sensing layers because of their structural instability at elevated temperature. Ordered mesoporous metal oxides synthesized by nanocasting, however show higher structural stabilities as compared to other materials with similar lateral dimensions in the nanometer range [1,2]. They also offer a good and reproducible gas interface due to their unique structural features [6]. To gain a deeper understanding of the stabilization mechanism a model based on two distinct processes for particle growth, namely coalescence [7] and Ostwald ripening [8],was proposed (see figure 1). Since the vapor pressure of metal oxides is very low, ripening via gas-phase transport is only a minor effect and coalescence is dominating. The nanocasting process typically involves a high temperature pre-treatment procedure of the material prior to removal of the rigid structure matrix. This often leads to pore walls with highaspect ratio crystallites. Along the wall the crystallites can be as large as $30 \mathrm{~nm}$ whereas their thickness is below $10 \mathrm{~nm}$; this dimension is suitable for gas sensing. Thermodynamically though, these nanostructures behave more like $30 \mathrm{~nm}$ particles. The thermal energy needed for re-orientation is higher than for $10 \mathrm{~nm}$ particles and therefore the stability is increased. a)

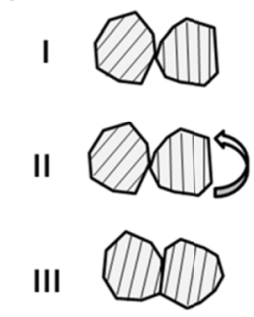

b)

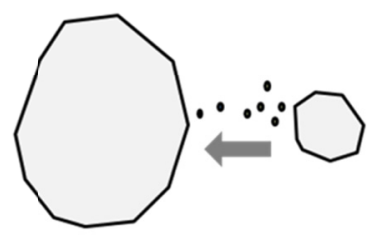

Fig. 1. Nanoparticle growth mechanisms: a) coalescence of non-aligned grains (I), crystal planes rearrange (II) and allow for fusion (oriented attachment) of the particles (III); b) Ostwald ripening: large grains grow at the expense of smaller grains via the gas phase.

To test this model samples with different crystallite sizes are synthesized and their thermal stability is investigated.

\section{Experimental}

A mesoporous silica matrix (KIT-6 [9]) was impregnated with molten indium nitrate pentahydrate $\left(\operatorname{In}\left(\mathrm{NO}_{3}\right)_{3} \cdot 5 \mathrm{H}_{2} \mathrm{O}\right.$; Sigma-Aldrich). After $24 \mathrm{~h}$ at $80^{\circ} \mathrm{C}$ in amuffle-type furnace 
indium nitrate was converted to indium oxide in a tube furnace at a temperature of $300^{\circ} \mathrm{C}$ with a heating rate of $2^{\circ} \mathrm{C} / \mathrm{min}$. For the variation of the crystallite size the sample was kept in an open vessel and a closed custom-built reactor respectively. The open vessel allows the air stream to carry the reaction gases away from the sample whereas the closed vessel prevents the nitrous gases generated during the conversion from being immediately removed. After conversion the silica matrix was removed by three times leaching with aqueous $\mathrm{NaOH}(5$ mol $\mathrm{L}^{-1}$ ) at $60^{\circ} \mathrm{C}$ for $1 \mathrm{~h}$. After each step the product was washed with distilled water until a $\mathrm{pH}$ of 7 was reached. The mesoporous indium oxide was finally dried in a muffle oven at $60^{\circ} \mathrm{C}$ for $24 \mathrm{~h}$.

The resulting samples were characterized with scanning electron microscopy (SEM), N2physisorption and powder X-ray diffraction (PXRD).

\section{Crystallite Size}

The lateral size of the crystalline domains of mesoporous In2O3 was varied by controlling the atmosphere during conversion.

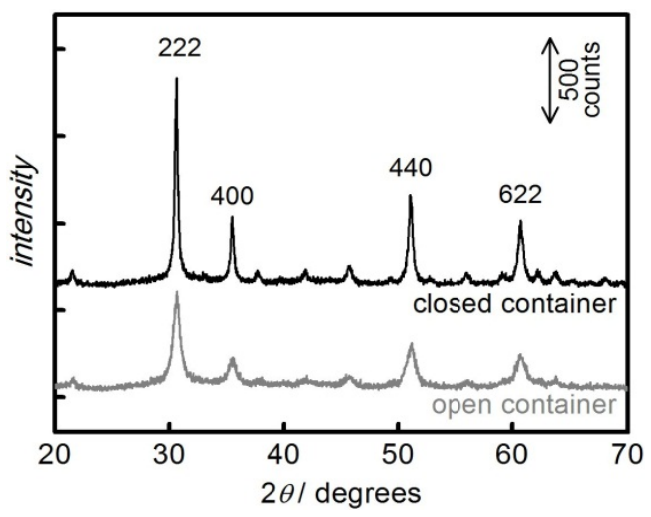

Fig. 2. Powder X-ray (PXRD) diffraction patterns of ordered mesoporous In2O3 prepared in a closed (red) andin an open (blue) vessel, respectively.

Figure 2showsthe PXRD diffraction patterns of the samples converted in an open and a closed reaction vessel. The sample prepared in the closed vessel exhibits narrower peaks.

Tab. 1.Crystallite sizes of mesoporous $\ln _{2} \mathrm{O}_{3}$ according to peak width analysis by Scherrer's method for various crystallographic directions.

\begin{tabular}{rcccc}
\hline & \multicolumn{4}{c}{$\ln _{2} \mathrm{O}_{3}$ crystallite size } \\
& \multicolumn{4}{c}{$($ in $h k /$ direction $) / \mathrm{nm}$} \\
& 222 & 400 & 440 & 622 \\
\hline open vessel & 13.4 & 14.2 & 11.6 & 11.7 \\
steel reactor & 30.1 & 27.9 & 21.1 & 19.3 \\
\hline
\end{tabular}

The crystallite size estimated by utilizing Scherrer's equation is twice as large size in all crystallographic directions as for the sample prepared in the closed vessel (see table 1).

\section{Porosity and Particle Structure}

The pore size distribution (BJH), the pore volume and the specific surface area (BET) determined by $\mathrm{N}_{2}$ physisorptionshow fundamental disparities. The sample converted in the open vessel (small crystals) exhibits a specific surface area of $90.2 \mathrm{~m}^{2} \mathrm{~g}^{-1}$. The pore volume is $0.38 \mathrm{~cm}^{3} \mathrm{~g}^{-1}$ and the pore size distribution shows three peaks at 4.37, 5.67 and $12.58 \mathrm{~nm}$ respectively (see figure 3 ).

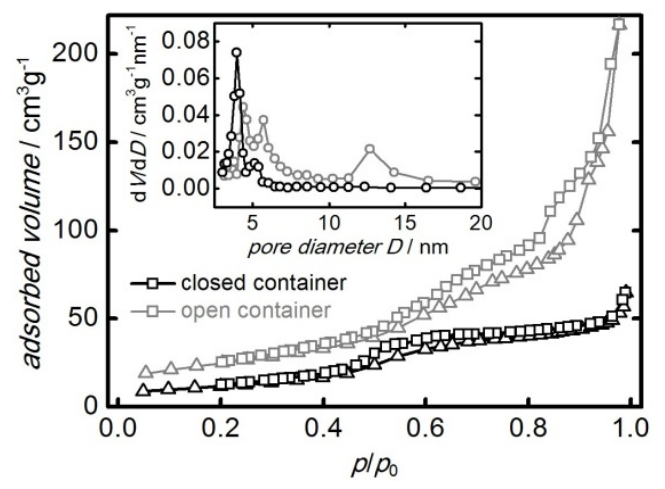

Fig. 3. $\mathrm{N}_{2}$ physisorption isotherms and pore diameter distributions of $\operatorname{In}_{2} \mathrm{O}_{3}$ prepared in a closed and in an open reactor.

The sample converted in the closed steel reactor (large crystallites) shows a distinct pore size distribution peak at $3.95 \mathrm{~nm}$. The specific surface area $\left(43.3 \mathrm{~m}^{2} \mathrm{~g}^{-1}\right)$ as well as the pore volume $\left(0.38 \mathrm{~cm}^{3} \mathrm{~g}^{-1}\right)$ are smaller compared to the open-vessel sample.

We attribute the described differences in porosity to a higher surface roughness of the pore walls caused by smaller crystallite sizes in the open vessel sample.

The overall sizes of the mesoporous particles were also found to be dependent on the synthesis process.

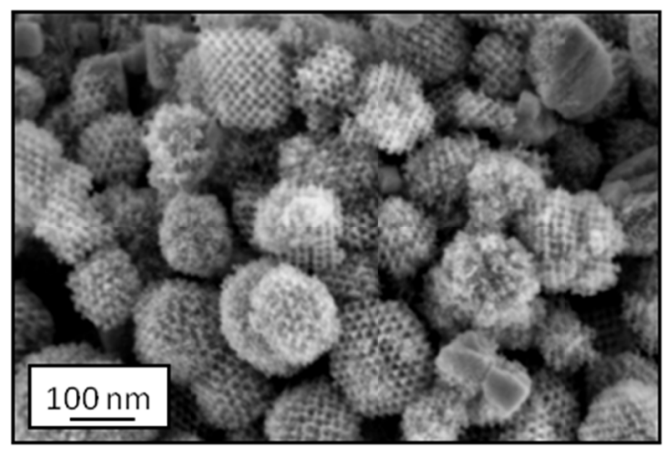

Fig. 4. Scanning electron microscopy (SEM) image of an $\mathrm{In}_{2} \mathrm{O}_{3}$ sample converted in an open vessel. 
For the open vessel the ordered mesoporous particles have diameters of ca. $200 \mathrm{~nm}$ (see figure 4) whereas particles of the sample converted in the closed reactor are more than 1 $\mu \mathrm{m}$ in diameter (not shown). However, the size of the mesostructured particles is likely not to influence the stability of the mesopore system.

\section{Thermal Stability}

After analyzing the structural properties of the two mesoporous samples the structural stability after treatment at variable temperature was investigated. The BET surface area is used as a measure for the quality of the mesoporous structure. Figure 5 shows the change in surface area after treatment in the range of $250^{\circ} \mathrm{C}$ and $700^{\circ} \mathrm{C}$ as a percentage of the initial surface area. An approximately linear decrease is observed up to $500^{\circ} \mathrm{C}$ for the sample converted in the open vessel (small crystallites) and up to $550^{\circ} \mathrm{C}$ for the sample converted in the closed container (large crystallites), respectively.

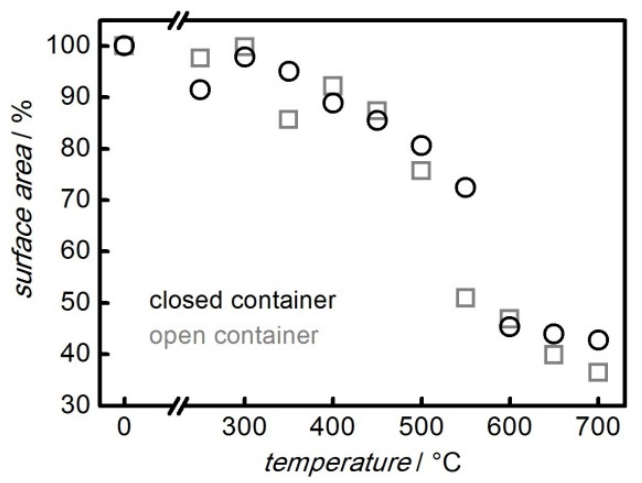

Fig. 5. Decrease of the BET surface area upon treatment at variable temperature for both mesoporous $\ln _{2} \mathrm{O}_{3}$ samples.

Above these temperatures a sudden steep decrease in the surface area is observed. For the sample with the large crystallites the temperature for this effect is ca. $50^{\circ} \mathrm{C}$ higher than for the sample with small crystallites.

This behavior can be explained by means of the proposed model. The linear decrease is attributed to ripening effects via the gas phase (Ostwald ripening). This leads to a smoothing of the pore walls and therefore to a slight decrease in the specific surface area. The steep decrease, on the other hand, is caused by the breakdown of the mesoporous structure which is caused by growth via coalescence.

\section{Conclusion}

Two ordered, mesoporous $\ln _{2} \mathrm{O}_{3}$ samples with different crystallite size were synthesized by varying the reaction vessel during the conversion of indium nitrate in a nanocasting route. Temperature treatments of the products and analysis of the morphological properties exhibit higher structural stability for the sample with larger crystallites, which is in accordance with the proposed model based coalescence as the main effect for mesopore structure breakdown. However, in addition to crystallite size other structure-related parameters, e.g. the specific surface area, may play a role; this will be subject of future investigation.

\section{Acknowledgements}

We thank the DFG (WA 2977/1-1) for financial support and Sabrina Amrehn for assisting at the synthesis of the $\ln _{2} \mathrm{O}_{3}$-samples.

\section{References}

[1] Waitz, T., Becker, B., Wagner, T., Sauerwald, T., Kohl, C.-D., Tiemann, M., Ordered NanoporousSnO${ }_{2}$ Gas Sensors with High Thermal Stability, Sensors and Actuators B: Chemical150, 788-793 (2010); doi: 10.1016/j.snb.2010.08.001

[2] Waitz, T., Wagner, T., Sauerwald, T., Kohl, C.-D., Tiemann, M., Ordered Mesoporous $\ln _{2} \mathrm{O}_{3}$ : Synthesis by Structure Replication and Application as a Methane Gas Sensor, Advanced Functional Materials19, 653-661 (2009); doi: 10.1002/adfm.200801458

[3] Sun, X., Shi, Y., Zhang, P., Zheng, C., Zheng, X., Zhang, F., Zhang, Y., Guan, N., Zhao, D., Stucky, G.D., Container Effect in Nanocasting Synthesis of Mesoporous Metal Oxides: Journal of the American Chemical Society, J. Am. Chem. Soc133, 14542-14545 (2011); doi: 10.1021/ja2060512

[4] Wagner, T., Sauerwald, T., Kohl, C.-D., Waitz, T., Weidmann, C., Tiemann, M., Gas Sensor Based on Ordered Mesoporous $\ln _{2} \mathrm{O}_{3}$ : Proceedings of $\mathrm{VI}$ International Workshop on Semiconductor Gas Sensors - SGS 2008, Thin Solid Films517, 61706175 (2009); doi: 10.1016/j.tsf.2009.04.013

[5] Yamazoe, N., New Approaches for Improving Semiconductor Gas Sensors, Sensors and Actuators B: Chemical5, 7-19 (1991); doi: 10.1016/0925-4005(91)80213-4

[6] Tiemann, M., Porous Metal Oxides as Gas Sensors, Chem. Eur. J13, 8376-8388(2007); doi: 10.1002/chem.200700927

[7] Huang, F., Zhang, H., Banfield, J.F., Two-Stage Crystal-Growth Kinetics Observed during Hydrothermal Coarsening of NanocrystallineZnS, Nano Letters3, 373-378 (2003); doi: $10.1021 / \mathrm{nl025836+}$

[8] Adamson, A.W., Gast, A.P. Physical chemistry of surfaces, 6th ed; Wiley: New York, 1997; ISBN: 0471148733

[9] Kleitz, F., Choi, S.H., Ryoo, R., Cubic la3d Large Mesoporous Silica: Synthesis and Replication to Platinum Nanowires, Carbon Nanorods and Carbon Nanotubes, ChemCommun (Camb), 2136-2137 (2003); doi: 10.1039/B306504A 